\title{
Justiça como práxis, capacidades humanas e saúde
}

| ${ }^{1}$ Carlos Dimas Martins Ribeiro |

Abstract: Este trabalho objetiva discutir uma perspectiva de justiça voltada para as capacidades e necessidades dos indivíduos e sua aplicação no campo da saúde. $\mathrm{Na}$ introdução, são feitas duas observaçôes gerais, com o intuito de contextualizar o tema da justiça distributiva ou social. Em seguida, explicita-se a visão ontológica dos seres humanos adotada nesta reflexão, baseada nos escritos do jovem Karl Marx. Em terceiro lugar, defende-se uma perspectiva da justiça - entendida como práxis - e sua aplicação no campo da saúde. Finalmente, são feitas algumas considerações, ressaltando a importância de estudos que conectem as reflexões sobre as teorias de justiça contemporâneas e as políticas públicas e, em especial, no campo da Saúde Coletiva, a partir da tradição marxista.

Key words: justiça social; capacidades e necessidades humanas; saúde; Karl Marx.
1 Instituto de Saúde da

Comunidade, Universidade

Federal Fluminense. Niterói-RJ,

Brasil. Endereço eletrônico:

dimasmribeiro@gmail.com

Recebido em: 21/02/1014 Aprovado em: 24/08/2014 
É necessário fazer, inicialmente, duas observações gerais sobre a justiça distributiva ou social. A primeira é que a justiça distributiva envolve duas circunstâncias, como caracteriza John Rawls (2003), sem as quais não emergiria um problema de justiça: a condição subjetiva do pluralismo moral e a condição objetiva de limitação de recursos. Se tivéssemos todos os recursos necessários para satisfazer nossas necessidades e acordo sobre que necessidades devem ser satisfeitas, não teríamos um problema de justiça.

O pluralismo moral pode ser exemplificado quando observamos as diferentes teorias de justiça distributiva e suas aplicações ao campo da saúde, as quais adotam diferentes concepções de saúde e respondem de maneiras diversas à questão do que deve ser igualado para alcançar a justiça no campo da saúde.

No caso da limitação de recursos na saúde - da lacuna entre os recursos disponíveis e as demandas existentes -, devem ser destacados seus componentes externo e interno (DENIER, 2007). O primeiro refere-se à natureza limitada dos recursos, em que a utilização dos recursos para obter determinados benefícios significa excluir outros benefícios que adviriam se os recursos fossem investidos de forma diferente. Em outros termos, trata-se da relação entre os recursos e o conjunto dos bens a serem distribuídos pelas instituições responsáveis, que incluem não apenas a saúde, mas outros bens igualmente importantes, como educação e trabalho, entre outros.

O segundo relaciona-se à intensificação, produzida socialmente, de nossas necessidades e desejos, de modo que a experiência da escassez se origina na impossibilidade de satisfazer nossas demandas ilimitadas (DENIER, 2007). Nesse contexto, devem-se salientar os processos sociais contemporâneos de medicalização da vida, operados hegemonicamente pelo complexo médicoindustrial-financeiro (MENDONÇA; CAMARGO JR., 2010). Contudo, a medicalização não é intrinsecamente negativa, sendo necessário analisar, nos contextos concretos, em que medida ela é justificável técnica e eticamente.

Não se supõe aqui que as circunstâncias de justiça possam ser superadas completamente, nem sequer em relação ao componente da limitação dos recursos, mas que sempre haverá algum desacordo entre os recursos que seremos capazes de mobilizar e nossas necessidades ou aspiraçôes. Isto mesmo que fosse 
possível construir uma condição futura de relativa abundância, no sentido de uma mudança da sociedade cujos recursos não seriam desviados para fins privados e seriam priorizados de forma adequada para satisfazer as necessidades relevantes dos indivíduos, ou no sentido de uma transformação econômica, social e cultural radical da sociedade. Compreendemos a limitação dos recursos como uma expressão da finitude dos seres humanos e devemos buscar uma valorização positiva dos limites humanos e uma atitude equilibrada para com as possibilidades das tecnologias em saúde, entre outras (DENIER, 2007).

A segunda observação é que a justiça distributiva se relaciona, de uma forma ou de outra, à noção de igualdade na distribuição de bens na sociedade, entre eles a saúde, requerendo uma estrutura institucional responsável por essa distribuição. Desta forma, as teorias de justiça procuram responder a duas questões fundamentais: quem são os concernidos e o que igualar para propósitos de justiça.

Em relação à primeira, a teoria pode contemplar no seu escopo, por exemplo, apenas os seres humanos ou incluir também os animais não humanos. Neste trabalho estamos defendendo uma perspectiva de justiça - aplicada ao campo da saúde -, considerando determinada visão ontológica dos seres humanos. Não é objetivo avaliar aqui se a perspectiva apresentada, baseada nos escritos do jovem Marx, pode ser estendida para incluir outros seres vivos, como os animais não humanos.

Em relação à segunda, como observa Sen (2001), toda concepção de justiça valoriza a igualdade num determinado espaço, divergindo sobre o objeto de valor que deve ser igualado. Desta forma, sendo os indivíduos tão diferentes em diversos aspectos - nas condições socioeconômicas, nas condições biológicas, nos talentos e nos planos de vida etc. -, o que se deve igualar para que haja justiça? Assim, para Ralws, o que deve ser igualado são os bens primários; para Nozick são as liberdades; para Dworkin são os recursos; e para Sen e Nussbaum, são as capacitações, caracterizando um contexto contemporâneo de pluralidade de concepções de justiça distributiva.

Dentro desta perspectiva, a relação entre equidade e igualdade pode ser definida em termos de meios e fins. A igualdade diz respeito ao que se pretende alcançar com a justiça, ao passo que a equidade está relacionada com as estratégias de pesquisa ou de políticas públicas que visam superar a desigualdade entre 
aqueles que alcançaram e os que não alçaram a igualdade pretendida. Num certo sentido, pode-se dizer que a equidade coloca a diferença em questões de justiça, na medida em que requer que sejamos sensíveis para as singularidades dos contextos concretos e atentos para as diferenças entre os indivíduos e grupos sociais que podem impedir a igualdade, em conformidade com a teoria de justiça utilizada.

\section{Visão ontológica dos seres humanos}

Para apresentar a perspectiva de justiça defendida neste trabalho, é necessário explicitar a visão ontológica dos seres humanos que está sendo adotada, baseada principalmente nos escritos do jovem Marx. Na concepção de Marx, os seres humanos - sua "natureza" ou "essência” - são constituídos por três componentes fundamentais: o empírico, o social e o histórico (PRUZAN, 1989).

O empírico porque os seres humanos são constituídos por um equipamento ou estrutura biológica - sua corporalidade - que especifica as capacidades e necessidades da espécie e do indivíduo (PRUZAN, 1989). O conjunto das capacidades e necessidades que caracteriza a identidade da espécie e de cada indivíduo somente pode ser determinado empiricamente considerando as particularidades dos contextos concretos e as singularidades dos indivíduos reais, e não de forma universal e a priori. Marx caracteriza o homem como um ser natural vivo que, por um lado, é munido de forças, pulsões ou capacidades vitais e, por outro, "é um ser que sofre, dependente e limitado" - um ser vulnerável -, carente de objetos externos indispensáveis para a manifestação de seus poderes vitais (MARX, 2004, p. 127).

Desta forma, Marx distingue capacidade humana de necessidade humana, estando este último conceito relacionado aos objetos, tais como comida, vestimenta, moradia, computador etc., necessários para a efetivação da vida do indivíduo, enquanto o primeiro refere-se às forças vitais que expressam a natureza dos seres humanos, como a capacidade de estar bem nutrido, a capacidade de estar abrigado e a capacidade de ler e escrever etc. (MARX; ENGELS, 2007; PRUZAN, 1989).

Para Marx (2004, p. 108), a vida é atividade, de modo que "ver, ouvir, cheirar, degustar, sentir, pensar, intuir, perceber, querer, ser ativo [e] amar", compreendidas como capacidades humanas, são, "no seu comportamento para com o objeto", o "acionamento da efetividade humana”. Como ser corpóreo, o homem é um ser sensível, isto é, um ser padecente que necessita de objetos fora de si - objetos de sua sensibilidade. Como argumenta Marx (2004, p. 128): 
[...] o homem enquanto ser objetivo sensível é, por conseguinte, um padecedor, e, porque é um ser que sente o seu tormento, um ser apaixonado. A paixão é a força humana essencial que caminha energicamente em direção ao seu objeto.

Para que as capacidades possam ser desenvolvidas e exercidas, elas devem ser colocadas para operar em um objeto, caso contrário elas não existem, exceto como uma possibilidade. A objetivação é a realização dos poderes de um indivíduo em um objeto, sem os quais ele não pode perpetuar sua existência conforme sua própria natureza ou essência (PRUZAN, 1989). Entre as necessidades humanas, Marx destaca aquelas vinculadas à "produção da vida material", condição fundamental que tem que "ser cumprida diariamente, a cada hora, simplesmente para manter os homens vivos" (MARX; ENGELS, 2007, p. 33). O pressuposto fundamental de toda a existência humana e, portanto, da história, é "que os homens têm de estar em condiçôes de viver para poder 'fazer história”" (MARX; ENGELS, 2007, p. 33).

O social porque, como Marx afirma em sua sexta tese sobre Feuerbach, a "essência humana", em sua realidade concreta, "é o conjunto das relaçôes sociais" (MARX; ENGELS, 2007, p. 534). Os seres humanos são essencialmente indivíduos sociais, embora em cada época histórica, a sociabilidade adquira determinadas formas.

O desenvolvimento da natureza própria do indivíduo e da espécie a que pertence somente pode ocorrer no seio da sociedade, pois é "na comunidade com outros que cada indivíduo tem os meios de desenvolver suas faculdades" e satisfazer suas necessidades, sendo esse processo, eminentemente, fenômeno social (MARX; ENGELS, 2007, p. 64). Assim, “o desenvolvimento de um indivíduo é condicionado pelo desenvolvimento de todos os outros, com os quais ele se encontra em intercurso direto ou indireto" (MARX; ENGELS, 2007, p. 422).

O histórico porque, nos diversos períodos, seus modos de produção característicos tanto expressam de forma diferente as capacidades e necessidades, como o desenvolvimento das forças produtivas amplia estas capacidades e necessidades (PRUZAN, 1989). Neste processo, modifica-se a própria natureza da espécie e dos indivíduos, vinculados de tal modo que o desenvolvimento dos poderes e necessidades do indivíduo e da espécie é mutuamente dependente (KAIN, 1988). No entanto, como argumenta Leopold, para Marx, os seres humanos possuem tanto "qualidades universais, constantes através da história 
e entre as culturas", como "qualidades variáveis, refletindo a diversidade histórica e cultural” (2007, p. 224). As primeiras são as que Marx refere como a "natureza humana no geral", e as últimas, como a natureza humana modificada historicamente (LEOPOLD, 2007, p. 224).

Entre as capacidades humanas, Marx destaca a capacidade de trabalhar, considerando que é através do "trabalho que o homem age sobre o mundo externo para produzir os meios de sua subsistência e desenvolver outras capacidades latentes" (MARX, 2004, p. 57). Como esclarece Lukács, o trabalho promove uma dupla transformação. Por um lado, "o próprio ser humano que trabalha é transformado por seu trabalho", modificando sua própria natureza e desenvolvendo seus poderes latentes (2012, p. 286). Além disso, "os objetos e as forças da natureza são transformados em meios de trabalho" e objetos para a satisfação das necessidades humanas (LUKÁCS, 2012, p. 286). Marx atribui "ao trabalho e a suas consequências - imediatas e mediatas - uma prioridade com relação a outras formas de atividade, o que deve ser entendido num sentido puramente ontológico" e não valorativo (LUKÁCS, 2012, p. 348). Uma atividade tem prioridade ontológica sobre outra simplesmente quando a primeira pode existir sem a segunda, enquanto o inverso não é possível. $O$ trabalho é o ponto de partida para a formação das capacidades e produção de objeto para a satisfação das necessidades humanas.

As capacidades humanas - e suas necessidades relacionadas - podem ser agrupadas em básicas, fundamentais para a preservação da vida, tais como comer, beber, estar abrigado, vestir-se etc., e os poderes mais elevados, tais como os vinculados à política, à ciência ou as artes etc. (KAIN, 1988). Como observa Pruzan, "uma vida que é dominada pela procura pelos meios para satisfazer necessidades materiais não é, para Marx, uma vida livre”, de modo que os indivíduos humanos "tornam-se genuinamente livres somente quando eles podem engajar-se em atividades que não são diretamente comprometidas na produção e satisfação de necessidades materiais" (PRUZAN, 1989, p. 169). Marx quer fundar a liberdade não no processo de trabalho (que ele chama de "realidade da necessidade"), mas no tempo livre (que ele chama "realidade da liberdade"), durante o qual os indivíduos podem desenvolver e exercer outras capacidades (LÖWY, 2012). 
Num contexto em que critica a divisão de trabalho em sociedades capitalistas,

em que o indivíduo passa a ter um campo de atividade determinado, se "não quiser perder seu meio de vida", Marx expressa uma visão do homem que para realizar-se precisa ter a oportunidade de exercer um conjunto mais amplo de capacidades do que aquelas vinculadas às necessidades de sobrevivência. Marx (2007, p. 38) argumenta que, em sociedades comunistas, cada indivíduo deverá poder "caçar pela manhã, pescar à tarde, à noite dedicar-[se] à criação de gado, criticar após o jantar", entendidas como capacidades humanas, de acordo com sua vontade, sem que ele se torne um "caçador, pescador, pastor ou crítico".

Duas outras capacidades são enfatizadas por Marx, conforme as análises de Gould (1983) e Peffer (1990): a capacidade de autodeterminação e a capacidade de autorrealização. Gould identifica o "estar livre de" ou liberdade negativa com autodeterminação, e o "ser livre para" ou liberdade positiva com autorrealização. Peffer, por outro lado, concebe a autodeterminação como incorporando a liberdade negativa e a liberdade positiva.

Para Gould (1983, p. 149), liberdade negativa é a superação das compulsões externas, podendo "tomar a forma de necessidade natural externa ou de necessidade social externa, ou seja, de domínio” e, para Peffer, a superação da indevida interferência de outro. Liberdade positiva é, para o primeiro, criação e realização da natureza própria, e para o segundo (1990, p. 123), oportunidade para determinar a própria vida, requerendo o "direito para igual participação em todos os processos de tomada de decisão social que afeta a vida" do indivíduo e o "direito para o igual acesso para os meios de autorrealização".

Finalmente, uma quarta capacidade deve ser mencionada: a participação na vida comunitária. Comunidade que, para Marx, pode ser descrita como "um grupo de indivíduos que partilha valores e um modo de vida", que se identifica com o grupo e suas práticas e se reconhece como membro (LEOPOLD, 2007, p. 235). Em adição, a visão de comunidade de Marx requer a igualdade (talvez não precisamente especificada) entre os indivíduos que operam com uma preocupação genuína uns com os outros. Isto requer que os indivíduos se relacionem de uma maneira que supere o mero autointeresse ou seja motivada unicamente pelos benefícios mútuos da cooperação (LEOPOLD, 2007). Nesta visão, a comunidade é uma condição e um produto do florescimento humano 
(LEOPOLDO, 2007): uma condição porque a comunidade é um requisito indispensável para o desenvolvimento e exercício das capacidades e satisfação das necessidades humanas; mas também um produto porque os seres humanos criam a comunidade ao ativarem sua própria natureza.

Em suma, para a visão ontológica apresentada aqui, os organismos humanos são concebidos como sistemas funcionais complexos dotados de uma gama de capacidades e padecentes de um conjunto de necessidades. Essas capacidades e necessidades expressam a natureza própria de cada espécie e de cada indivíduo, dentro desta espécie. Elas são constitutivas da própria identidade da espécie e dos indivíduos.

\section{Justiça como práxis}

Inicialmente, é importante mencionar quatro razōes gerais, inter-relacionadas, pelas quais a perspectiva de justiça defendida neste trabalho se diferencia das abordagens contemporâneas de justiça (RAWLS, 2003; DWORKIN, 2005; SEN, 2010; NUSSBAUM, 2007) e seus desdobramentos no campo da saúde (DANIELS, 2008; SEGALL, 2010; VENKATAPURAM, 2011; RUGER, 2010). Não é objetivo deste trabalho aprofundar tais questões, mas apenas situar a abordagem de justiça defendida aqui.

Tomamos como pressuposto, como argumenta Marx, que a igualdade deve ser pensada como práxis, isto é, como consciência e o comportamento do "homem a respeito do outro homem como seu igual" (MARX, 2011, p. 51). A igualdade é a "unidade essencial humana" para a "identidade prática do homem com o homem, quer dizer, para a relação social ou humana do homem com o homem" (2011, p. 51).

Como práxis, entende-se, de modo geral, a ação transformadora do mundo, em relação às circunstâncias em que os homens vivem e ao próprio homem. Trata-se do "esforço de superação da oposição abstrata entre fatos e valores, pensamento e ação, teoria e prática", onde uns e outros estão "ligados no interior de um único movimento" em que, por um lado, "a explicação e a crítica do real estão dialeticamente integradas", e por outro, a teoria se materializa em atos (LÖWY, 2012, p. 40).

A primeira razão é que essas abordagens operam com a separação entre a dimensão normativa e a descritiva, desconsiderando a articulação entre essas 
dimensões. Para os propósitos de uma perspectiva de justiça como práxis, é necessário construir ou adotar tanto uma teoria ética que "provê um conjunto de princípios ou padrões morais pelos quais julgar os arranjos sociais", quanto oferecer uma teoria social que "provê critérios para decidir entre conjuntos opostos de arranjos sociais historicamente possíveis" (PEFFER, 1990, p. 3). Para a justiça como práxis, não basta apenas interpretar "o mundo de diferentes maneiras; o que importa é transformá-lo”, como diz Marx na décima primeira tese sobre Feuerbach (2007, p. 535).

A segunda razão é que estas perspectivas igualmente separam a esfera do consumo da esfera da produção, com um foco voltado para "a distribuição equitativa de produtos", sem considerar que "a produção, considerada como uma totalidade orgânica”, determina o consumo (PRUZAN, 1989, p. 160). Para Marx, na interação entre produção e consumo, a primeira tem prioridade ontológica sobre a segunda, no sentido de que a produção é o momento predominante, sem o qual o consumo não seria possível (LUKÁCS, 2012). A produção é aqui entendida de forma ampla, como produção e reprodução da vida humana, indo muito além da mera conservação biológica para adquirir uma dimensão econômico-social.

A justiça como práxis não se restringe ao consumo, mas considera, de forma mais ampla, as relações sociais entre os agentes, "por meio das quais levam a cabo sua atividade produtiva comum e sua distribuição dos benefícios da sociedade" (GOULD, 1983, p. 232). Neste sentido, "uma mudança da produção deve ocorrer para que uma correspondente mudança na distribuição possa” acontecer, de forma que Marx "rejeita a noção que um modo de distribuição na sociedade pode substancialmente ser alterado sem considerar os requisitos do modo dominante de produção" (PRUZAN, 1989, p. 160).

A terceira razão é que essas concepções adotam como pressuposto o sistema capitalista e consideram que é possível realizar a justiça em sociedades cindidas em classes e reguladas pela propriedade privada dos modos de produção. Para a justiça como práxis, no capitalismo, a realização dos direitos humanos poderá representar - se é que isto é possível - a emancipação política, no sentido de serem garantidos alguns direitos de cidadania vinculados às capacidades e necessidades básicas, mas não a emancipação humana, que para ser realizada requer a efetivação da totalidade das capacidades e necessidades constitutivas do florescimento humano, como veremos abaixo (MARX, 2010; LEOPOLD, 2007). 
O capitalismo é um sistema econômico e social intrinsecamente injusto, na medida em que seu modo de operar está baseado na exploração e alienação. A emancipação humana é somente possível com uma transformação profunda do sistema econômico e social em que vivemos e uma mudança radical da subjetividade humana. Não é objetivo deste trabalho explorar a natureza injusta do sistema capitalista e aprofundar os conceitos de exploração e alienação, mas consideramos necessário indicar a natureza geral desta injustiça, o que faremos no item a seguir.

Finalmente, em quarto lugar, essas abordagens se dirigem ao conjunto dos seres humanos, desconsiderando as diferentes inserçōes dos indivíduos no modo de produção capitalista e os conflitos de classe decorrentes de sua dinâmica interna. Este sistema gera formas de dominação em várias esferas do campo social - e suas diferentes vítimas -, que embora decorrentes de seu modo de produção, adquirem autonomia relativa com seus determinantes específicos.

Desta forma, a justiça como práxis pretende adotar, prioritariamente, a posição de um universo particular de concernidos humanos, reunidos no que Dussel (2012) chama, na sua Ética da Libertação, a comunidade das vítimas (dominados e excluídos) do sistema vigente - operário, índio, mulher, negros, raças discriminadas, idosos, crianças, populações de rua, populações LGBT (lésbicas, gays, bissexuais, travestis e transexuais), refugiados, empobrecidos, geraçôes futuras etc. A comunidade das vítimas reúne aqueles cuja vida ou corporalidade foi negada - expressa no seu sofrimento -, isto é, aqueles que têm uma má vida, uma vida desprovida das condiçôes adequada de produção, reprodução e desenvolvimento.

O ponto de partida da Ética da Libertação é um "julgamento de fato" existem vítimas resultantes das normas, ações, microestruturas, instituições, políticas públicas, serviços de saúde etc. do sistema atual - seguido de um "julgamento de valor" que considera a presença das vítimas como eticamente negativa, traduzindo-se em análises da vitimização e em ações para transformar este sistema (ou parte dele). Mas nada disso é possível sem o "reconhecimento da igualdade do outro sujeito, da vítima," enquanto ser vivente e, simultaneamente, o tornar-se responsável pelo outro (DUSSEL, 2012, p. 375).

Nada disso significa que essas abordagens não tenham elementos que possam ser relevantes para a construção da perspectiva de justiça que defendemos neste 
trabalho. Alguns conceitos desenvolvidos por estas abordagens podem ser integrados coerentemente à justiça como práxis. Entre as abordagens de justiça contemporâneas, a "Abordagem dos Funcionamentos Seguros" (WOLFF; DESHALIT, 2007) e a "Perspectiva dos Funcionamentos Básicos" (DIAS, 2014a), têm uma proximidade maior com a justiça como práxis, já que elegem como objeto de valor - para propósitos de justiça e políticas públicas - os próprios funcionamentos e não a liberdade de funcionamento. Em outro trabalho, em coautoria, trabalhamos a aplicação desta última perspectiva para o campo da saúde (RIBEIRO; DIAS, 2014).

Para a justiça como práxis, a justiça requer a produção da vida de cada indivíduo humano concreto - entendido como um sistema funcional complexo (dinâmico e interativo) dotado de capacidades e funcionamentos e padecente de necessidades -, de modo que ele possa florescer ou expressar sua própria natureza. Essas capacidades podem ser desdobradas em seus elementos constitutivos, que são os funcionamentos que compóem cada capacidade. A noção de funcionamentos (functioning), de origem aristotélica, foi recuperada no debate contemporâneo sobre justiça por Amartya Sen (2010) e Martha Nussbaum (2007). Ela se refere à capacidade de ser e fazer, e inclui funcionamentos de diferentes níveis de complexidade, tais como ver e ouvir, saber ler e escrever, a participação política e a preocupação com outros seres humanos. Estes funcionamentos pode também ser vistos como capacidades e desdobrados nos seus elementos mais fundamentais, que são os próprios funcionamentos. Para que os seres humanos possam desenvolver e exercer as capacidades e os funcionamentos e satisfazer suas necessidades, são requeridas condições materiais de existência adequadas.

Entre as capacidades e funcionamentos, podem-se distinguir dois grupos, nos escritos do jovem Marx, conforme podemos deduzir da lista de necessidades coletadas por Leopold (2007). Os grupos expressam a distinção, feita por Marx, entre as "capacidades básicas" ou relativas à preservação da vida, listadas no primeiro grupo, e os "poderes mais elevados", citados no segundo. O primeiro grupo tem prioridade ontológica sobre o segundo, já que o indivíduo precisa estar vivo para desenvolver e exercer os poderes mais elevados, embora os dois grupos sejam fundamentais para o florescimento humano.

O primeiro grupo - preservação da vida ou básicos - inclui capacidades essenciais para a sobrevivência dos indivíduos humanos, tais como nutrição 
(alimentação, bebida etc.), abrigo (vestuário, habitação etc.), condições climáticas (iluminação, ar etc.), locomoção (exercícios físicos etc.), higiene (limpeza etc.), atividade sexual e reprodutiva e trabalho. E o segundo grupo - poderes mais elevados - é composto de capacidades tais como recreação (dançar, cantar etc.), cultura (fazer teatro etc.), educação e exercício intelectual (pensar, engajar-se em aprendizagem, comprar livros etc.), expressão artística (pintar etc.), satisfação emocional (amar etc.), prazer estético (ouvir música etc.), além das capacidades mencionadas anteriormente, quais sejam, de autodeterminação, autorrealização e a participação na vida comunitária.

Neste sentido, a justiça como práxis elege como objeto de valor, para propósito de justiça e políticas públicas, as próprias capacidades (com seu conjunto de funcionamentos) e as necessidades relacionadas, e não a autonomia - e suas capacidades correlacionadas, como a capacidade de trabalhar, de autodeterminação, de autorrealização e de participação na vida comunitária -, delimitando o universo dos concernentes a um subgrupo de indivíduos humanos que podem desenvolver e exercer tais capacidades. Isto porque a escolha das capacidades e necessidades nos permite incluir aqueles seres humanos que não podem, temporária ou definitivamente, exercer ou desenvolver esta capacidade, tais como crianças, deficientes mentais ou idosos com demência.

Desta forma, diferentemente de Dussel, não consideramos ser necessário o reconhecimento do outro como um sujeito autônomo, para assumir a responsabilidade pelo outro, de cuja vitimização, nas palavras de Dussel, "sou (somos) causa cúmplice, pelo menos por ser um ser humano, destinado à responsabilidade comunitária da vulnerabilidade compartilhada de todos os viventes" (DUSSEL, 2012, p. 378). Basta o reconhecimento do outro como um ser vivente, dotados de capacidades ou poderes vitais, sendo eticamente errado impedir seu florescimento ou que ele seja o tipo de criatura que é, sem desconsiderar o valor da autonomia para um subgrupo de indivíduos humanos. Pela mesma razão, nos afastamos da abordagem proposta por Sen (2010) e Nussbaum (2007), que elegem como objeto de valor a capacitação (capability), compreendida como a liberdade de escolher uma combinação de capacidades e funcionamentos (DIAS, 2014b). A liberdade de escolha é uma das capacidades relevantes para ser promovida, naqueles indivíduos que têm a possibilidade de exercê-la, desde que certas condições econômicas, sociais e culturais sejam satisfeitas. 
Nesta perspectiva, adota-se uma concepção de vida humana multidimensional, incorporando o exercício de um conjunto amplo, variado e complexo de capacidades, funcionamentos e necessidades que, conforme já dissemos, apenas podem ser definidas empiricamente e não de forma universal e a priori. As capacidades e necessidades fundamentais dos seres humanos e de cada indivíduo, incluindo as básicas e os poderes mais elevados, apenas podem ser conhecidas ou através de pesquisas ou de experiências que desenvolvemos na relação com o outro. Enfim, devemos ouvir diferentes vozes - certamente os indivíduos objeto de nossa consideração -, mas também os familiares, os profissionais de saúde, os gestores, entre outros.

$\mathrm{Na}$ determinação das capacidades, funcionamentos e necessidades dos indivíduos, devemos ter o cuidado para não projetarmos nossas próprias necessidades nos seres humanos que tomamos como objeto de conhecimento ou de preocupação ética, considerando determinadas capacidades como relevantes, em detrimento das circunstâncias particulares vivenciadas pelos diversos indivíduos e das capacidades fundamentais que constituem sua própria identidade (DIAS, 2014b). Em oposição a isto, podemos desenvolver nossa capacidade imaginativa para ampliar nossa sensibilidade para demandas que, sem a qual, poderiam ser imperceptíveis. Este é um processo de contínua atenção refinada às singularidades do outro, inerente à sua forma de vida e existência concreta (DIAS, 2014b).

$\mathrm{Na}$ perspectiva adotada neste trabalho, os problemas de justiça não se restringem aos arranjos institucionais, sendo as institucionais entendidas como instrumentos para promover as capacidades e funcionamentos e satisfazer as necessidades dos indivíduos e grupos. Incluem também os padrões de conduta dos atores sociais no cumprimento da justiça, entre eles os gestores e os profissionais de saúde (SEN, 2010). Isto significa que as condições para a realização da justiça não dependem somente dos fatores distributivos (bens e serviços), mas também de fatores relacionais envolvendo os diferentes agentes (POGGE, 2004).

Desta forma, incorpora-se uma visão de justiça passiva, "que dirige a atenção ética para aqueles cuja justiça e injustiça é experimentada”, tanto como um conceito de justiça ativa, que estabelece um lugar essencial para os agentes que "compartem a responsabilidade para a justiça e injustiça” (POGGE, 2004, p. 143). São considerados os vários graus de responsabilidade que se podem imputar a estes diferentes agentes, conforme suas respectivas funções nos diversos níveis da sociedade. 


\section{Capitalismo, injustiça e a comunidade das vítimas}

Marx considera um ser humano normal aquele indivíduo que é capaz de exercer suas capacidades e satisfazer suas necessidades, considerando o padrão de normalidade - empiricamente e socialmente determinado - do que um ser humano pode ser e fazer (PRUZAN, 1989). Desta forma, cada sociedade constitui um padrão de normalidade entendido como o conjunto de capacidades, funcionamentos e necessidades tornado disponível pela atividade produtiva.

Este padrão de normalidade tem uma função descritiva e normativa. Por um lado, identifica o conjunto de capacidades e necessidades humanas que emerge no processo histórico, fruto do desenvolvimento das forças produtivas; por outro, constitui um referencial para avaliar a falta de oportunidade dos indivíduos em manifestar tais capacidades e satisfazer essas necessidades. Certamente, existe um exercício avaliativo para determinar, entre o conjunto das capacidades e necessidades, quais são boas e, entre elas, quais são essenciais para propósitos de justiça social.

Da mesma maneira, quando Marx discute a exploração e a alienação intrínseca ao modo de produção capitalista, enquanto elementos necessários para a valorização do capital, ele está operando, num movimento único, com uma descrição dos processos de exploração e alienação concreta em que estão sujeitos os indivíduos, nesse modo de produção específico, mas, sobretudo, com uma avaliação ética deste contexto, considerado injusto. Dentro desta interpretação, em sociedades capitalistas, justifica-se e perpetua-se uma ordem social que impede os indivíduos de realizarem o padrão de normalidade de sua sociedade, negando a uma grande maioria dos indivíduos o desenvolvimento de suas capacidades e a satisfação de suas necessidades, estando disponíveis as condições para isto, dentro do modo de produção dominante (PRUZAN, 1989).

$\mathrm{Na}$ análise de Marx, o capitalismo tende a reduzir "a carência do trabalhador a mais necessária e mais miserável subsistência da vida física", como se "o homem não [tivesse] nenhuma outra carência, nem de atividade, nem de fruição" (MARX, 2004, p. 141). Cálculo da "vida como (existência) mais escassa possível" - como autorrenúncia à vida e ao conjunto das carências humanas -, como norma universal, "vigente para a massa dos homens" (MARX, 2004, p. 141). Nesta perspectiva, uma existência desumana quando há uma situação de vida 
contrária à natureza humana, em que os indivíduos são impedidos de ter acesso aos objetos que satisfaçam suas necessidades e as condiçõos para o exercício de suas capacidades. (MARX, 2011).

Neste sentido, o capitalista tem interesse em prolongar a duração da jornada de trabalho, diminuindo o tempo livre do trabalhador e, dentro dessa jornada, delimitar o tempo de trabalho necessário para a reprodução do trabalhador ao mínimo indispensável. Mais fundamentalmente, tem o interesse de "extrair da força de trabalho do trabalhador tanta mais-valia quanto seja possível”, aumentando o tempo de trabalho não pago, necessário para reprodução do capital (PRUZAN, 1989, p. 115). O trabalhador, ao contrário, tem interesse em diminuir a jornada de trabalho (sem diminuição do salário), estendendo seu tempo livre, e em aumentar, dentro desta jornada, o tempo de trabalho necessário para sua reprodução, considerando a satisfação de suas necessidades, amplamente consideradas. A redução da jornada de trabalho e o aumento do tempo livre têm importância fundamental na autorrealização dos seres humanos, além da satisfação das necessidades materiais. Trata-se de uma condição essencial para a promoção de um amplo conjunto de capacidades humanas, exercidas através de atividades políticas, sociais e culturais, entre outras.

Além disso, para Marx, o trabalhador sofre de um duplo estranhamento: "estranhamento da coisa" e "estranhamento-de-si" (MARX, 2004, p. 83). Estranhamento da coisa porque o produto do trabalho lhe é um objeto estranho. O trabalho não mais produz apenas objetos necessários para os trabalhadores e os indivíduos não se apropriam dos produtos que eles criam com seu trabalho, em muitos casos nem sequer para sua própria sobrevivência (KAIN, 1988; PEFFER, 1990). Estranhamento-de-si porque a relação do trabalhador com o ato de produção opera de modo que sua atividade parece não lhe pertencer. Como analisa Marx (2004, p. 82), o trabalhador "não se afirma [no trabalho], mas negase nele", isto é, "não desenvolve nenhuma energia física e espiritual livre", mas autossacrifício, de modo que "o trabalhador só se sente [...] junto a si [quando] não trabalha e fora de si [quando] no trabalho". Ele não tem controle sobre o processo de trabalho, que ainda que seja fonte de valor, perdeu completamente o significado para o próprio trabalhador. E finalmente, os indivíduos se alienam em relação a sua própria pessoa e aos outros, isto é, a suas potencialidades individuais e o que pode ser feito junto com outros indivíduos (PEFFER, 1990). 
Em suma, o capitalismo restringe a autodeterminação dos seres humanos em relação à vida e ao trabalho, limita sua autorrealização no desenvolvimento de sua potencialidade e ocasiona a perda do sentido de pertencimento a uma comunidade humana e, desta forma, não realiza a natureza ou essência dos seres humanos, impedindo seu florescimento (PEFFER, 1990).

\section{Justiça como práxis e a capacidade de ser saudável}

Entre as capacidades básicas, a capacidade de ser saudável deve assumir lugar fundamental, seja porque esta tem um valor em si mesma, no sentido de que, de modo geral, valorizamos esta capacidade, mas também porque ela possui um valor instrumental, sendo condição essencial para o exercício de outras capacidades.

Nesta direção, podemos pensar numa interdependência entre os funcionamentos que compõem a capacidade de ser saudável - como, por exemplo, a capacidade de estar bem nutrido e a de estar livre de enfermidades evitáveis -, tanto como entre a capacidade de ser saudável e outras capacidades, como a de estar empregado. Segundo esta visão, a saúde não é um bem supremo que deve ser alcançado a qualquer custo, porém é parte - junto com o trabalho, a educação e a política, entre outros bens - da qualidade de vida de um indivíduo, considerando as várias etapas de um ciclo de existência - nascimento, infância, adolescência, fase adulta, velhice e morte.

O exercício da capacidade de ser saudável, em particular, requer um conjunto de condições que normalmente se denomina determinantes sociais de saúde. Neste ponto, devem-se destacar as contribuições da epidemiologia social, que apesar das diferentes opções teóricas, modelos explicativos e vertentes de trabalho, compartilham a "insistência em investigar explicitamente os determinantes sociais do processo saúde-doença" (2005, p. 8), pressupondo a ideia da realidade como uma totalidade complexa, "organizada hierarquicamente em diferentes dimensões” (BARATA, 2005, p. 15). Várias concepções críticas da epidemiologia desenvolvidas na América Latina seguem esta orientação. Entre as mais relevantes, estão a "epidemiologia das classes sociais", de Jaime Breilh, a teoria do "processo de produção e saúde", de Asa Cristina Laurell, e a "teoria dos modos de vida e saúde", de Almeida Filho (2004). Entre estas, nas várias dimensões do processo saúde-doença - e, podemos acrescentar, do cuidado -, incluem-se o modo de produção e reprodução social, as condições de vida e trabalho, a divisão social 
de trabalho, a posição social dos indivíduos, as redes de apoio social, os estilos

de vida, as predisposições biológicas, além do acesso aos serviços de saúde, entre outros (BUSS; PELLEGRINI, 2007).

Não é objetivo deste trabalho discutir os diferentes modelos explicativos dos determinantes sociais da saúde e suas formas de articular e hierarquizar estes diversos componentes. Contudo, alguns conceitos propostos por Breilh nos parecem relevantes para os propósitos de uma justiça como práxis. No domínio da saúde, o autor destaca três planos de análise e intervenção: o observável, o atual e o real. O observável diz respeito ao que observamos de imediato nos pacientes (sintomas e sinais); o atual refere-se aos processos generativos e determinantes micros, incluindo os modos de vida das classes sociais, raças e gêneros, entre outros grupos sociais; e o real abarca os dois planos anteriores acrescidos dos processos gerais ou macros.

Nesse contexto, o autor distingue os “"processos destrutivos' ou deteriorantes, no caso dos que provocam uma deterioração ou piora da qualidade de vida, e os 'processos protetores' ou benéficos, no caso dos que contribuem favoravelmente para seu desenvolvimento e aperfeiçoamento" (BREILH, 2006, p. 67). Supõe-se que

[...] os processos do viver transformam-se em destrutivos e processos protetores, conforme as relações sociais que funcionam, em campos distintos, como o mais 'geral' da sociedade em seu conjunto, o campo 'particular' de seus grupos e o campo 'singular' das pessoas em sua cotidianidade (BREILH, 2006, p. 67).

Breilh (2006) enfatiza a existência de uma "tríplice iniquidade", considerando as formas de subordinação, exploração e desumanização social em relação à classe, à etnia e ao gênero, em processos que não são totalmente desvinculados e que têm sua origem comum na acumulação e concentração do poder. Nesta perspectiva, a "iniquidade" não se refere à injustiça na repartição e no acesso de bens e serviços, entre eles os serviços de saúde, mas ao processo intrínseco que a gera.

De qualquer maneira, dentro da perspectiva de justiça que estamos adotando, o modelo explicativo e de intervenção no processo saúde-doença-cuidado deve ser capaz de contemplar as condições para o desenvolvimento e exercício das capacidades - com os funcionamentos que as constituem -, considerando as interações entre essas capacidades e funcionamentos. Deve permitir explicar as diferenças na distribuição dessas condições entre os grupos sociais e indivíduos no interior da sociedade que permitem satisfazer as necessidades, acessando os 
bens sociais e os fatores de conversão para transformar esses bens nas capacidades relevantes, incluindo fatores nos vários planos mencionados acima.

Nesta direção, podemos pensar nos processos protetores e destrutivos mencionados acima como, respectivamente, processos capacitantes e (des) capacitantes. Neste sentido, a distinção feita por Wolf e De-Shalit (2007), entre "desvantagens corrosivas" e os "funcionamentos férteis", é importante. As "desvantagens corrosivas" são aquelas que têm efeitos negativos sobre outras desvantagens, na medida em que a ausência do exercício de um funcionamento obstrui a realização de outros. Os "funcionamentos férteis" são aqueles que, quando garantidos, espalham seus efeitos benéficos sobre outros funcionamentos.

\section{Considerações finais}

No Brasil, de modo geral, existe uma lacuna entre as discussões sobre teorias de justiça distributiva contemporânea e as políticas públicas, excetuando algumas poucas contribuições, em particular no campo da Saúde Coletiva. Nas investigações acadêmicas sobre equidade em saúde, predominam estudos empíricos sobre a desigualdade em saúde, sobretudo relacionados ao acesso à saúde e aos serviços de saúde, porém sem explicitar uma noção de justiça e de saúde. Adota-se, de forma implícita, uma perspectiva de justiça como igualdade dos recursos, compreendidos, na maioria das vezes, como bens e serviços.

Neste trabalho, procuramos trazer uma contribuição para preencher esta lacuna, discutindo uma perspectiva para pensar e agir em questôes de justiça, um caminho que requer, evidentemente, muitos aprofundamentos. Uma abordagem que pode ser utilizada para estudos empíricos, por exemplo, avaliando em que medida processos macros (políticas públicas etc.) e micros (serviços de saúde etc.) promovem a capacitação ou (des)capacitação dos indivíduos e satisfazem suas necessidades, conforme assinalado.

Também podemos ouvir diferentes vozes para determinar as capacidades, funcionamentos e necessidades fundamentais, em vários grupos de indivíduos, tais como os indivíduos com síndrome de Down ou os transexuais, entre outros. Essas listas podem servir de parâmetro para os processos de avaliação indicados acima; no entanto, nenhuma delas, evidentemente, substitui a análise dos casos concretos formados por indivíduos reais e suas singularidades. 
ALMEIDA-FILHO, N. Modelos de determinação social das doenças crônicas nãotransmissíveis. Ciênc Saúde Coletiva. Rio de Janeiro, v. 9, n. 4, p. 865-884, 2004.

BARATA, R. B. Epidemiologia Social. Rev Bras Epidemiol. Rio de Janeiro, v. 8, n. 1, p. 7-17, 2005.

BREILH, J. Epidemiologia crítica. Ciência emancipadora e interculturalidade. Rio de Janeiro: Fiocruz, 2006. 317 p.

BUSS, P.M.; PELLEGRINI FILHO, A. A saúde e seus determinantes sociais. PHISIS: Revista de Saúde Coletiva. Rio de Janeiro, v. 17, n. 1, p. 77-93, 2007.

CAMARGO JR, K.R. Medicalização, farmacologização e imperialismo sanitário. Cad Saúde Pública. Rio de Janeiro, v. 29, n. 5, p. 844-846, 2013.

DANIELS, N. Just health. Meeting health needs fairly. New York: Cambridge University Press, 2008. 397 p.

DENIER, Y. Efficiency, justice and care. Philosophical reflections on scarcity in health care. The Netherlands Baixos: Springer, 2007. 301 p.

DIAS, M.C. Em defesa de um ponto de vista moral mais inclusivo. In.: (Org.). A perspectiva dos funcionamentos: em defesa de uma abordagem moral mais inclusiva, 2014a. No prelo.

Teorias de justiça. In: . (Org.). A perspectiva dos funcionamentos: em defesa de uma abordagem moral mais inclusiva, 2014b. No prelo.

DUSSEL, E. Ética da libertação na idade da globalização e da exclusão. Petrópolis: Vozes, 2012. 672 p.

DWORKIN, R. A virtude soberana. A teoria e a prática da igualdade. São Paulo: Martins Fontes, 2005. 689 p.

GOULD, C.C. Ontologia social de Marx. Individualidad y comunidad em la teoria marxista de la realidad social. México: Fondo de Cultura Econômica, 1983. 246 p.

KAIN, P.J. Marx and ethics. New York: Oxford Univerity Press, 1988. 222 p.

LEOPOLD, D. The young Karl Marx. German philosophy, modern politics, and human flourishing. New York: Cambridge University Press, 2007. 323 p

LÖWY, M. A teoria da revolução no jovem Marx. São Paulo: Biotempo, 2012. 216 p.

LUKÁCS, G. Para uma ontologia do ser social I. São Paulo: Boitempo, 2012. 434 p.

MARX, K. Manuscritos econômicos-filosóficos. São Paulo: Boitempo, 2004. 175 p. . Sobre a questão judaica. São Paulo: Boitempo; 2010. 139 p.

MARX, K.; ENGELS, F. A ideologia alemã. São Paulo: Boitempo, 2007. 614 p. 

- A sagrada família. São Paulo: Boitempo, 2011. 286 p.

MENDONÇA, A.L.O.; CAMARGO JR., K.R. Complexo médico-industrial-financeiro: os lados epistemológico e axiológico da balança. PHYSIS: Revista de Saúde Coletiva. Rio de Janeiro, v. 22, n. 1, p. 215-238, 2012.

NUSSBAUM, M. Frontiers of justice. Disability. Nationality. Species membership. Cambridge: Harvard University Press, 2007. 487 p.

PEFFER, R.G. Marxism, morality, and social justice. New Jersey: Princeton University Press, $1990.526 \mathrm{p}$.

POGGE, T.W. Relational conceptions of justice: responsibilities for health outcomes. In.: ANAND, S.; PETER, F.; SEN, A. (Orgs.). Public health, ethics, and equity. New York: Oxford University Press, 2009. p. 135-161.

PRUZAN, E.R. The concept of justice in Marx. New York: Peter Lang, 1989. 238 p.

RAWS, J. Justiça como equidade. Uma reformulação. São Paulo: Martins Fontes, 2003. 306 p.

RIBEIRO, C.D.; DIAS M. C. Saúde e doença à luz da perspectiva dos funcionamentos. In: DIAS, M.C. (Org.). A perspectiva dos funcionamentos: em defesa de uma abordagem moral mais inclusiva, 2014. No prelo.

RUGER, J.P. Health and social justice. New York: Oxford University Press, 2010. 276 p.

SEGALL, S. Health, luck, and justice. New Jersey: Princeton University Press, 2010. 239 p.

SEN, A. A ideia de justiça. Coimbra: Almedina. 2010. 585 p.

. Desigualdade reexaminada. Rio de Janeiro: Record, 2001. 301 p.

VENKATAPURAM, S. Health justice. Massachussetts: Polity Press, 2011. 270 p.

WOLL, J.; DE-SHALIT, A. Disadvantage. New York: Oxford University Press, 2010. 231 p.

\section{Agradecimento}

O autor agradece ao Dr. Rodrigo de Souza Filho, da Universidade Federal de Juiz de Fora, pela leitura crítica do artigo, que contribuiu para sua maior clareza e coerência. 
Justice as praxis, human capabilities and health This article discusses a perspective of justice focused on the capabilities and needs of individuals and their application in the field of health. In the introduction, two general observations are made in order to contextualize the theme of distributive or social justice. Next, the ontological view of human beings based on the writings of the young Karl Marx is outlined. Thirdly, a perspective of justice - understood as praxis - and its application in the field of health are defended. Finally, some concluding remarks are made, which emphasize the importance of studies that connect the reflections on contemporary theories of justice and public policy and in particular in the field of public health within the Marxist tradition.

> Palavras-chave: social justice; capabilities and human needs; health; Karl Marx. 